\title{
Visão de mundo em livros didáticos de biologia. Um estudo sobre o conceito ecossistema
}

Francisco Ângelo Coutinho

Rogério Parentoni Martins

Raquel Reis Winter

Fernanda de Jesus Costa

\begin{abstract}
Resumo
Há consenso sobre que uma educação científica adequada não é a que se executa abordando somente conteúdos e conceitos específicos das ciências naturais. Uma educação científica adequada deveria também destacar os elementos representacionais do conhecimento científico, os que oferecem idéias sobre a estrutura e funcionamento do mundo. Analisamos o conceito de ecossistema, tal como é utilizado na Ecologia científica, na perspectiva de duas concepções metafísicas ocidentais de significados opostas. Esta análise nos serve como fundamento para verificar como tal conceito é tratado pelo livro didático de biologia. Há evidências de preferências pelo emprego de uma metafísica de substância ao invés de uma metafísica de processos, esta mais adequada à natureza da Ecologia.
\end{abstract}

Palavras-chave: Visão de mundo, ensino de Ecologia, livro didático, ecossistema

\section{Abstract}

Worldview in biology textbooks. A study of the ecosystem concept.

There is consensus among education experts that adequate scientific education will never be achieved through strict focus on content and concepts specific to the Natural Sciences. It must also emphasize the representational elements of scientific knowledge i.e. those that offer insights into the structure and functioning of the world. Here, we examine the concept of ecosystem, as presented to Ecology students, from the perspective of two opposing, Western metaphysical frameworks. This analysis is used as background against which we investigate how that concept is treated in Biology textbooks. We find that the 
metaphysics of substance is favored over the metaphysics of process, which we believe to be more adequate to ecological thinking.

Keywords: Worldview, ecological education, text book, ecosystem

\section{Introdução}

Tornou-se amplamente aceito que a educação científica em ciências naturais não é somente sobre conteúdos e conceitos específicos (veja MATTEWS, 2009). Mais do que isso, uma educação científica deveria "enfatizar elementos sobre a ciência, sua natureza, seus métodos, bem como seus aspectos sociais, ideológicos e históricos" (HOVARDAS e KORFIATIS, 2010). Esta linha de raciocino destaca a necessidade de se explicitar os elementos representacionais do conhecimento científico, entendidos como os que oferecem idéias sobre a estrutura e funcionamento do mundo. Tais elementos constituiriam o que é denominado "visão de mundo" (HOVARDAS e KORFIATIS, 2010; MATTEWS, 2009). Esta vertente considera a "educação científica como uma forma de reflexão" de tal modo que explicite as relações entre ciência e sua filosofia (TSEITLIN e GALILI, 2006).

Entendido como um sistema de crenças interligadas (DeWITT, 2010, p. 7), "visão de mundo" refere-se ao amálgama de crenças epistemológicas, ontológicas e acordos éticos, bem como posições religiosas ou não religiosas mantidos por uma pessoa e/ou cultura (MATTEWS, 2009). Por exemplo, a "visão de mundo aristotélica" incluia crenças tais como "a Terra situa-se estacionada no centro do Universo" e "o mundo supra lunar é constituído de uma quinta substância, denominada éter". Tais crenças não fazem parte da visão de mundo proporcionada pela ciência contemporânea, embora possam ser mantidas por certas pessoas dentro de nossa cultura ocidental.

Neste artigo analisamos qual seria a visão de mundo propagada por livros didáticos de biologia. Esta análise se justifica pelo fato de o livro didático desempenhar um importante instrumento de mediação no processo de ensino/aprendizagem de biologia, que informa o aluno sobre elementos representacionais da ciência. Assim, partimos da pergunta: "como o livro didático caracteriza os fenômenos do mundo em seu nível mais básico?" Como esta questão refere-se à visão que temos da realidade em seu nível mais fundamental, entramos na da filosofia da ciência. Esta, de modo mais geral, estrutura sua análise a partir de duas grandes perspectivas: epistemologia e metafísica (LADYMAN, 2002, p. 5). 
A epistemologia se preocupa com o conhecimento e sua justificação por meio da formulação de questões tais como: o que é o conhecimento, em oposição à mera crença? Como poderemos estar seguros de que sabemos alguma coisa? Qual é a fonte do conhecimento (os sentidos ou a razão)? O que é o método científico?

A metafísica se preocupa com a natureza última das coisas, sobretudo como o mundo se comporta em seu nível mais fundamental. Assim, metafísica é uma teoria da realidade (FERRÉ, 1996, p. 1), cuja tarefa é traçar as possibilidades de ser a fim de proporcionar um entendimento sobre a estrutura da realidade como um todo, em seu nível mais fundamental (LOWE, 2006). Questões metafísicas são: o que são as leis da natureza? O que significa dizer que alguma coisa é causa de outra? (LADYMAN, 2002, pp. 7-8).

Collingwood já havia percebido, em 1945, a íntima relação entre a ciência e seus fundamentos filosóficos:

The detailed study of natural fact is commonly called natural science, or for short simply science; the reflection on principles, whether those of natural science or of any other department of thought or action, is commonly called philosophy.... but the two things are so closely related that natural science cannot go on for long without philosophy beginning; and that philosophy reacts on the science out of which it has grown by giving it in future a new firmness and consistency arising out of the scientist's new consciousness of the principles on which he has been working (Collingwood apud Mattews, 2009). ${ }^{1}$

E continua:

For this reason it cannot be well that natural science should be assigned exclusively to one class of persons called scientists and philosophy to another class called philosophers. A man who has never reflected on the principles of his work has not achieved a grown-up man's attitude towards it; a scientist who has never philosophized about his science can never be more than a secondhand, imitative, journeyman scientist. (Collingwood apud Mattews, 2009)².

1 "O estudo detalhado do fenômeno natural é normalmente conhecido como ciência natural ou, resumidamente, apenas ciência; a reflexão sobre princípios ou sobre qualquer outra área de pensamento ou ação é comumente chamada filosofia... porém as duas são tão intimamente relacionadas que a ciência natural não pode ir longe sem uma iniciação filosófica e que a filosofia, mesmo estando a parte, atua sobre a ciência para lhe dar uma base firme, proporcionando ao cientista uma nova consciência sobre os princípios com os quais ele tem trabalhado". (Tradução do segundo autor).

2 "Por isso não é bom que a ciência natural deva ser atribuída exclusivamente a uma classe de pessoas chamada cientistas e a filosofia a outra chamada filósofos. Um homem que nunca tenha refletido sobre os princípios filosóficos que fundamentam seu trabalho não terá uma atitude

R. B. E. C. T., vol 4, núm 2, mai./ago. $2011 \quad$ ISSN - 1982-873X 
Segundo Mattews (2009), essa exigência de "uma reflexão sobre os princípios" como sendo necessária para a prática da boa ciência, também serve para que se tenha uma boa prática sobre o ensino de ciência.

Há um volume enorme de livros e artigos sobre epistemologia; porém são poucos os estudos dedicados aos aspectos metafísicos da ciência, em geral (ULANOWICZ, 2009, p. 8), e sobre educação científica, em particular. Todavia, recentemente, alguns autores começam a entender que questões metafísicas são centrais para uma filosofia da ciência e para a educação científica (REINERS e LOCKWOOD, 2009, p. 16). Nesta perspectiva objetivamos explicitar aspectos metafísicos da visão de mundo difundida em livros didáticos de biologia.

Contudo, analisar todos os conteúdos do livro didático é praticamente impossível, impertinente e foge ao escopo de um artigo científico. Por esse motivo estabelecemos um recorte analítico ao tratarmos sobre ecologia. Mais especificamente, analisaremos o conceito "ecossistema", pois deste modo será possível uma análise em maior profundidade.

Ecossistema é um dos mais importantes conceitos das ciências biológicas, pois tem a função heurística de tornar a grande complexidade própria deste nível de organização ecológica tratável. Isto porque o conceito abrange a ação de alguns processos e permite identificar propriedades emergentes, tais como ciclagem de nutrientes e fluxo de energia (O'NEILL, 2001). Há autores que o consideram o grande conceito unificador da ecologia (PEACOCK, 2008, p. 351), ou unidade básica dessa ciência (TANSLEY, 1935). A par disso, a ecologia de sistemas é atualmente considerada responsável pela condução da ciência contemporânea (FERRÉ, 1996, p. 316), isto é, a ciência que fornece os conceitos e métodos para o entendimento das complexas relações que compõem a realidade.

A escolha do tema justifica-se, ainda, pelo fato de a ecologia, por suas características e objetos de estudo, ser a ciência pela qual o funcionamento da natureza é descrito e, desta forma, origina vários conhecimentos que informam ao cidadão sobre a realidade. Finalmente, compreender a natureza da ecologia científica é condição compulsória para quem se interesse por educação ambiental e a compreensão pública de questões sobre manejo e conservação da natureza (HOVARDAS e KORFIATIS, 2010).

Considerando-se a importância desta última proposição é oportuno referirmos a Dewey (1910):

madura com relação a ele; um cientista que nunca filosofou sobre sua ciência não passará de um cientista de segunda mão". (Tradução do segundo autor). 
One of the only two articles that remain in my creed of life is that the future of our civilization depends upon the widening spread of the scientific habit of mind; and that the problem of problems in our education is therefore to discover how to mature and make effective this scientific habit' (DEWEY apud Mattews, 2009).

Para que se crie este "hábito científico da mente" é preciso que a educação científica considere seriamente as proposições advindas das reflexões filosóficas sobre o que a ciência é, ou seja, quais seriam suas características epistemológicas e quanto metafísicas. Caso contrário, o ensino de ciência corre o risco de se resumir à memorização de um volume enciclopédico de conceitos (Emmeche e El-hani, 2000; Kawasaki e El-hani 2002), ao invés de contribuir para que os alunos possam criar um "temperamento científico" (Nehru apud Matthews, 2009).

\section{Aportes metodológicos}

Primeiramente, procuramos entender os significados do conceito de ecossistema tal como ele aparece na Ecologia contemporânea. Trata-se de uma metodologia de análise que considera os resultados da pesquisa científica. Deste modo, nosso alvo foi o conceito de ecossistema em um artigo de revisão sobre o tema (O'Neill, 2001).

Outro aspecto diz respeito à análise do conceito em livros didáticos. Como os trechos que se referem ao conceito eram muito curtos e, por conseguinte, a discussão sobre o conceito não estava aprofundada, optamos por uma análise de conteúdo, entendida como um conjunto de técnicas que visam a interpretar o conteúdo das unidades sob análise (veja-se, por exemplo, Bardin, 2000). Nos livros didáticos amostrados marcarmos as palavras-chave que caracterizavam o entendimento sobre ecossistemas e que poderiam estar vinculada a certas concepções metafísicas de acordo com a análise prévia do conceito de ecossistema, tal como encontrado em nossa revisão.

\section{Concepções metafísicas de substância e processo}

A metafísica de substâncias tem raízes profundas na cultura ocidental e sua proposição é a de que as coisas possuem uma natureza íntima que faz com que elas sejam o que são, em outras

3 "Um dos apenas dois artigos que integram meu "credo de vida" é o de que o futuro de nossa civilização depende de uma ampla difusão do modo científico de pensar; e que o maior dos problemas para nossa educação é o de descobrir como amadurecê-lo e torná-lo efetivo". (Tradução do segundo autor). 
palavras, sem a qual não poderão ser o que na realidade são. Tal natureza íntima seriam as propriedades essenciais ou substância características de determinada entidade, sem a qual esta não poderia pertencer à categoria. No transcurso da história da filosofia, houve muitas tentativas de encontrar tais propriedades essenciais, por exemplo, por meio de definições precisas. Houve épocas nas quais o conhecimento verdadeiro era concebido como aquele capaz de captar as essências.

Embora o substancialismo remonte a alguns dos primeiro filósofos ocidentais, Platão e Aristóteles foram os que a sistematizaram. Segundo Platão, o mundo sensível está metafisicamente fundado em essências (eidos), as verdadeiras realidades. Estas estariam situadas em um mundo meta-sensível. O mundo como o percebemos seria uma cópia imperfeita dessa realidade supra-sensível, eterna e imutável. O conhecimento mais elevado (noêsis) seria a apreensão dessas formas eternas. O conhecimento do mundo sensível, mutável, seria o de mera opinião (doxa). Tal apreensão dar-se-ia por recordação do mundo supra-sensível que a alma um dia experenciou. O que Platão propôs foi uma teoria sobre a natureza dos conceitos, de acordo com a qual conhecer algo é recordar-se de sua natureza essencial (Reale, 1994, Vol. II, pp. 153161).

Aristóteles parte de um ponto distinto (Lear, 1995, p. 269): o que existe é a coisa individual ou substância (ousia) (Ross, 1987, p. 172); os indivíduos seriam compostos de matéria (hylé), o princípio de individuação, e forma (eidos), a essência ou a natureza íntima. Cada coisa individual é a forma realizada na matéria (Lear, 1995, p. 280). Portanto, a forma seria o que há de universal no indivíduo. Deste modo, João e Pedro diferem em suas matérias, mas possuem a mesma forma, pois ambos são Homens. Para Aristóteles, os indivíduos carregam em si mesmos as condições de sua própria definição.

O platonismo e o aristotelismo se comprometem com a idéia de que as coisas encontram nas essências suas fundamentações ontológicas, ou seja, o que possibilita a existência de uma determinada coisa é a sua essência. Esta concepção influenciou fortemente as tradições filosófica e científica subseqüentes, inclusive no estabelecimento da crença de que os seres individuais poderiam ser agrupados em categorias bem determinadas e o conhecimento sobre esses seres se daria por meio da apreensão da essência da categoria em questão. Tal apreensão se daria por meio de conceitos que seriam justamente as expressões mentais das essências das categorias. Sob esta expectativa tem-se a definição de um conceito como expressão das características necessárias e suficientes da categoria. Formalizando: $(x)\{(x \in \Gamma) \leftrightarrow P x\}$, em que $\Gamma$ é uma categoria qualquer e P é a propriedade necessária e suficiente para pertencer a essa categoria. Disso, definir $\lceil$ seria exatamente expressar " $\mathrm{P}$ " e expressar " $\mathrm{P}$ " seria referir-se exatamente à categoria $\Gamma$. 
Uma metafísica alternativa ao essencialismo foi desenvolvida por vários filósofos. Rescher (1996 e 2000) a denominou metafísica de processo. Sua proposição fundamental é a de que "mudança" e "desenvolvimento" sejam os descritores mais adequados da realidade (Hustwit, 2007). Embora grande parte do desenvolvimento da metafísica de processo ocorresse durante o século XX, por meio de filósofos como Whitehead (1978 [1929] e Rescher (1996 e 2000), seu precursor foi Heráclito (aprox. 540-470 a.C) (Rescher, 1996, p. 1 e Rescher, 2008). Além disso, foi considerada por Hegel, Peirce, William James e Bergson, entre outros (Rescher, 1996, capítulo 1). O que caracterizaria a metafísica de processo na história da filosofia não seria simplesmente reconhecer os processos naturais como iniciadores de tudo na natureza, mas a insistência de estes constituiriam o aspecto fundamental do real (Rescher, 1996, p. 8). Whitehead e Rescher adotaram o princípio Bergsoniano "a natureza é um processo" (Rescher, 2000, p. 4) para mostrar que devemos reconhecer a temporalidade, a historicidade, a mudança e a passagem como fundamentais para a nossa compreensão sobre o mundo.

Heráclito inicia esse modo de pensar (Rescher, p. 9). Ao comparar a realidade ao fluir de um rio - "De quem desce o mesmo rio vêm ao encontro águas sempre novas" (frag. 12, apud Reale, vol. 1, p. 64) - Ele marca a perenidade de todas as coisas e o fato de que nada permanece em estado de imobilidade e estabilidade:

Esta ordem, idêntica para todas as coisas, não a fez nenhum dos Deuses, nem os homens, mas era sempre, é e será fogo eternamente vivo, que em medida se acende e em medida se apaga (frag. 30, apud Reale, vol. 1, p. 68).

Desta maneira, ele atribui ao fogo o fundamento de todas as coisas e não a uma substância material. A variação de diferentes estados e condições do fogo produz toda mudança. O devir é, sem dúvida, o aspecto central da doutrina de Heráclito e que se tornou célebre na fórmula "tudo flui" (panta rhei). Ele reconhecia o mundo não como uma coleção de coisas, mas uma constelação de processos (Rescher, 1996, p. 10). Whitehead, no século XX, também instituiu o processo como a categoria central de sua filosofia, considerando o tempo, a mudança e a criatividade seus fatores metafísicos distintivos (Rescher, 1996, p 20).

Portanto, a metafísica de processo prioriza a atividade, ao invés da substância; o vir-a-ser, ao invés do produto; a mudança, ao invés da persistência; e, finalmente, a novidade, ao invés da continuidade (Rescher, 1996, p. 31). A metafísica de processos se interessa pelo modo como as coisas se comportam ao invés de como elas são em sua essência. No quadro I contrastamos a metafísica de processo e a metafísica de substância: 
Quadro 1. Contraste conceitual entre metafísica de substância e metafísica de processo (Modificado a partir de Rescher, 1996, p. 35).

\begin{tabular}{|c|c|}
\hline Metafísica de Substância & Metafísica de Processos \\
\hline Individualidades discretas & Relação interativa \\
\hline Separação & Totalidade \\
\hline Condição (fixidez da natureza) & Atividade \\
\hline Uniformidade da natureza & Inovação/Novidades \\
\hline Estabilidade classificatória & Fluidez e evanescência \\
\hline
\end{tabular}

Até agora esboçamos o que os dois tipos de metafísica são. Apesar de ser um esboço, o julgamos suficiente para mostrar a perspectiva de que os objetos do mundo podem ser compreendidos sob a perspectiva metafísica de substância ou de processo. Sob esta última, o mundo não é considerado um aglomerado de objetos e coisas, mas de processos e relações que originam objetos e entidades não estáticos (DeWitt, 2010). Em seguida argumentaremos sobre como esta perspectiva metafísica é mais adequada para facilitar a compreensão sobre os conceitos utilizados em ecologia.

\section{A compreensão científica do conceito ecossistema}

O'Neill (2001) destaca a importância do conceito de ecossistema como um paradigma para o estudo dos sistemas ecológicos. Quando foi criado por Tansley, em 1935, o conceito ecossistema estava associado a uma visão da natureza como algo relativamente constante. A teoria de Análise de Sistemas fez com que o conceito de estabilidade passasse a fundamentar ainda mais essa noção de natureza em constante estado de equilíbrio. Por exemplo, segundo O'Neill, a idéia de estabilidade sustenta a definição de ecossistema de Eugene P. Odum, dada em 1953:

“(...) natural unit that includes living and nonliving parts interacting to produce a stable system in which the exchange of materials between the living and nonliving parts follows circular paths (...)" (Odum apud O'Neil, 2001)'.

1 "Unidade natural que abrange o conjunto de seres vivos e de materiais inorgânicos os quais interagem a fim de constituir um sistema estável no qual o intercâmbio de materiais entre ambos segue trajetórias circulares". (Tradução do segundo autor). 
Esta concepção de ecossistema, a qual chamaremos tradicional, é sustentada por uma visão associada à Análise de Sistemas que estabelece uma analogia entre ecossistema e máquina; e esta se tornou central para muitos ecólogos (O'Neill 2001). O que garante essa visão do conceito de ecossistema, em particular, e da natureza, em geral, é a filosofia mecanicista, ou seja, a doutrina de que todos os fenômenos do universo são melhor explicados por meio de princípios mecânicos (Peirce, 1998 [1935], p. 5).

De certa forma, essa analogia teve seus méritos, pois permitiu uma visão holística das propriedades do sistema, tais como ciclagem de nutrientes, e facilitou a comunicação de conceitos ecológicos com o público. Porém, segundo O’Neill, há problemas lógicos e científicos associados a este conceito e ao da analogia com a máquina. Considerando os problemas enfrentados pelo conceito de ecossistema, nossa intenção é a de buscar os elementos representacionais inerentes à visão de mundo da ecologia. Começaremos abordando os conceitos de "fechamento estrutural", "homogeneidade espacial" e "estabilidade" que expressam propriedades que supostamente definiriam o ecossistema como unidade de organização em ecologia. Para atingir esse objetivo nos valeremos da concepção de ecossistema defendida por O'Neill à qual chamaremos contemporânea.

A concepção tradicional de ecossistema faz uso da noção de fechamento estrutural, pois considera que esta unidade ecológica estaria ocupando um espaço específico. Classicamente, citase como exemplo uma microbacia para os sistemas terrestres ou um lago para os sistemas aquáticos. Os limites espaciais que o definiria foram obviamente considerados abertos, caso contrário não haveria intercâmbio de organismos, energia e matéria dos quais o sistema dependeria para manter sua estrutura e função. No entanto, este conceito de ecossistema assume que as interações e loops de feedback necessários e suficientes para explicar sua dinâmica ocorreriam em determinados limites espaciais.

Segundo O'Neill, o problema com este pressuposto da concepção tradicional é o de que a distribuição espacial das populações componentes do ecossistema pode ser muito mais ampla do que os limites do ecossistema. Alternativamente, a concepção contemporânea propõe que a área mínima necessária para se definir o ecossistema não seja o limite do ecossistema local, mas a amplitude de dispersão dos seus componentes bióticos. Porém, embora seja mais realista, considerar dispersão como indicadora de área de ecossistema provoca dificuldades metodológicas e operacionais em estudos empíricos, pois em um ecossistema haverá necessariamente uma diversidade de organismos como amplitudes de dispersão distintas.

A concepção tradicional exige que ecossistemas tenham homogeneidade espacial. O que torna crítica a adoção de tal pressuposto é que uma maior amplitude de área seria exigida para 
manter toda uma gama de populações necessárias à estabilidade do sistema. Tal como uma espécie muito especializada, um ecossistema espacialmente homogêneo pode não responder a mudanças e, por isso, tornar-se-ia instável. Nesse caso, a concepção contemporânea propõe que a faixa potencial de dispersão não seja constante e uniforme e que a homogeneidade espacial dependa da escala de observação.

Finalmente, a concepção tradicional afirma que ecossistemas são entidades estáveis. No entanto, estabilidade também depende da escala de observação. Por exemplo, quando consideramos todo o espectro espaço-temporal de distúrbios, percebemos que ecossistemas são instáveis. A estabilidade é perceptível somente em escalas temporais reduzidas. Dado tempo suficiente, a probabilidade de eventos catastróficos torna-se igual a 1,0. Neste caso, a concepção contemporânea propõe que a estabilidade de um ecossistema local dependa da escala de tempo de observação. Curiosamente, Clements (1916) que propôs o conceito de super-organismo para caracterizar a sucessão em comunidades vegetais, preconizava que a sucessão seria temporalmente caracterizada em um intervalo de 10 a 300 anos. O que ocorresse antes e depois não seria sucessão ecológica e, portanto, não influenciaria na ocorrência deste processo.

\section{Resultados da análise da concepção científica quanto ao conceito de ecossistema}

Nosso objetivo a partir daqui é o de encontrar os fundamentos metafísicos que sustentem a concepção clássica e a concepção contemporânea. O quadro 1 (seção 2 desse artigo) mostra o contraste conceitual entre metafísica de substância e metafísica de processo e é com base nele que nossa análise ocorrerá.

O primeiro par de conceitos refere-se à individualidades discretas, como elemento conceitual da metafísica de substância, em oposição à relação interativa característica da metafísica de processos. Nossa análise mostrou que a concepção clássica fundamenta-se no conceito de fechamento estrutural, enquanto a concepção contemporânea foca o conceito de um ponto de vista interacional. Esta visão relacional também vincula a concepção contemporânea ao elemento conceitual de totalidade, em oposição ao de separação, satisfazendo também os critérios da metafísica de processo no que diz respeito ao segundo par de conceitos do quadro 1.

Quanto ao terceiro par de conceitos, condição $X$ atividade, a concepção tradicional fundamenta-se em uma visão estática da realidade, enquanto a concepção contemporânea focaliza na atividade sua crítica ao conceito de estabilidade, pois a estabilidade depende da escala em que se observa. Esta característica é salientada por Rescher (2008): "as coisas duradouras não são mais do que padrões de estabilidade em um mar de processos". Os conceitos de 
heterogeneidade $\mathrm{e}$ instabilidade também minam a visão tradicional de uniformidade $\mathrm{e}$ estabilidade, pois a novidade (o intercâmbio e dispersão de organismos) bem como a heterogeneidade espacial e a instabilidade ao longo do tempo seriam a regra.

A análise do conceito de ecossistema, fundamentada em concepções metafísicas, nos revela visões de mundo cientificamente estruturadas e diametralmente opostas. Tal conclusão é corroborada pela filosofia da ecologia segundo a qual "para se compreender os sistemas vivos, a ênfase deve mudar de leis fixas para a descrição do processo" (Ulanowicz, 2009, p. 117). Em seguida, a análise do conceito de ecossistema em livros didáticos de biologia nos revelará qual das duas concepções metafísicas é empregada pelos diversos autores destes livros.

\section{0 conceito ecossistema em livros didáticos de biologia}

Foram analisados os nove livros de biologia para o ensino médio, aprovados no PNLDEM2009- MEC. Conforme o quadro 2:

Quadro 2. Livros didáticos de biologia analisados

\begin{tabular}{|c|c|}
\hline Livros analisados & Autores e ano \\
\hline Bio - volume único & Lopes e Mendonça (2006) \\
\hline Biologia: Biologia das Populações - volume 3 & Amabis e Martho (2009) \\
\hline Biologia Hoje - volume 3 & Linhares e Gewandsjander (2008) \\
\hline Biologia - volume 3 & Wilson Paulino (2008) \\
\hline Biologia 3 - volume 3 & César e Sezár (2005) \\
\hline Biologia - volume único & Favaretto e Mercadante (2005) \\
\hline Biologia - volume único & Adolfo, Crozeta e Lago (2005) \\
\hline Biologia - volume único & J. Laurence (2005) \\
\hline Biologia 2 - volume 2 & Oswaldo Frota-Pessoa (2008) \\
\hline
\end{tabular}

Em Adolfo, Crozeta e Lago (2005), o ecossistema é definido como “(...) conjunto de interações, formado pelo ambiente físico (fatores abióticos) e a comunidade (fatores bióticos). Os fatores abióticos correspondem aos componentes físico-químicos do ambiente, como o solo, a água, o ar, a temperatura, a salinidade, a pressão. Já os fatores bióticos são constituídos pelos seres vivos" (p. 15). Assim, nesta definição é explícita a interação entre os fatores vivos e os abióticos no ecossistema, demonstrando que ele apresentaria uma estrutura fechada. Deste modo, de acordo com a visão tradicional. 
Em seguida, esses autores afirmam que "O ecossistema é uma estrutura auto-sustentável que deve apresentar 3 níveis básicos de seres vivos: os produtores, os consumidores $e$ os decompositores" (p. 15). Aqui é claro que a idéia de auto-sustentabilidade localiza o conceito na visão tradicional, pois auto-sustentabilidade sugere um sistema fechado.

Em Amabis e Martho (2009), "O termo ecossistema foi utilizado pela primeira vez em 1935 pelo ecólogo inglês Arthur Tansley (1871-1955) para descrever uma unidade em que seres vivos (biocenose) e componentes não vivos (biótopo) interagem, formando um sistema estável" (p. 328). Mais uma vez está presente a concepção tradicional, que afirma ser ecossistema uma unidade fechada e estável.

Em seguida, os autores afirmam que "Os princípios que definem um ecossistema aplicam-se em todas as escalas, desde um pequeno lago até o nível planetário. Assim, um ecossistema pode ser tanto uma floresta, um lago, uma ilha ou um recife de corais como um aquário autosuficiente, com plantas, peixes, bactérias, algas, etc" (p. 328). Neste trecho as idéias de fechamento e estabilidade se consolidam.

César e Sezar (2005) definem o ecossistema da seguinte maneira: "O ecossistema tem uma parte biótica, viva, representada pela comunidade, e uma parte abiótica, não viva, que inclui todos os fatores físicos e químicos do ambiente. Os ecossistemas podem ser pequenos, como uma lagoa ou grandes, como a Floresta Amazônica. Independentemente de seu tamanho, em todos eles ocorre um intercâmbio de matéria e energia. Além disso, cada ecossistema também troca matéria e energia com os ecossistemas vizinhos" (p.306). Aqui a idéia de haver interação entre os componentes é explícita como também o é a de que os limites de um ecossistema depende da dispersão de seus componentes. Deste modo a concepção destes autores é mais próxima à contemporânea.

Favaretto e Mercadante (2005) definem: "Um ecossistema é um sistema auto-sustentado, que inclui fatores bióticos (comunidade) e fatores abióticos (físicos e químicos)" (p. 9). Ao considerar o ecossistema como auto-sustentado, e nada mais dizer sobre suas propriedades, a definição compromete-se com uma visão tradicional.

Laurence (2005) define no capítulo 2 (Vida e Energia) ecossistemas como "conjuntos dinâmicos, pois seus diversos componentes interagem permanentemente" (p.33). No capítulo 4 (Ecossistemas e populações) os 'conjuntos dinâmicos' são definidos como "populações que interagem entre si e com os fatores abióticos do meio, em determinado local e em um mesmo intervalo de tempo" (p. 62). Neste caso, a natureza dinâmica dos ecossistemas poderia ser exemplificada pelo "fato de seres vivos servirem de alimento para outros seres vivos e a alteração da atividade vital em função das variações climáticas nas diferentes épocas do ano" (p. 33). As 
variações ocorrem, mas "há um relativo equilibrio, o equilibrio ecolóqico, que garante a preservação das diferentes formas vivas" (p. 33). Ao enfatizar o dinamismo existente entre os seres vivos de um ecossistema, Laurence aproxima sua definição da concepção contemporânea de ecossistema, porém, a dinâmica e o equilíbrio entre as populações ocorre em "determinado local", o que evidencia uma estrutura estável e fechada.

De acordo com Linhares e Gewandsjander (2008), "A reunião e a interação da comunidade com o ambiente físico formam um sistema ecológico ou ecossistema. Uma floresta, com sua vegetação, seus animais, seu tipo de solo e seu clima característico, é um ecossistema, assim como um lago, um oceano um tronco de árvore e um simples aquário" (p. 326). Aqui, percebe-se uma determinação rígida dos limites, deixando claro que o ecossistema é constituído por seus próprios componentes, desconsiderando-se, sobretudo, a abertura e interação com outros ecossistemas.

Em Lopes e Mendonça (2006) vê-se: "O conjunto formado pela comunidade e pelos componentes abióticos que atuam sobre ela corresponde ao ecossistema. Assim, a palavra ecossistema é um termo técnico para a palavra natureza. O conjunto de todos os ecossistemas da Terra, ou seja, a camada da Terra que contem seres vivos forma a biosfera" (p.297). Embora críticas severas possam ser feitas a essa definição, pois se imagina que a natureza seja mais ampla do que a biosfera, nota-se aqui uma intenção de entender os ecossistemas como entidades abertas, o que a aproximaria da visão contemporânea de ecossistema. No entanto, adiante, afirmam que "Os ecossistemas são (...) unidades funcionais básicas em que os componentes bióticos e abióticos interagem e estão inseparavelmente relacionados" (p.297). Neste trecho há a idéia de fechamento estrutural e, assim, podemos interpretar a visão propagada por este livro oscilando entre a concepção tradicional e a contemporânea do conceito de ecossistema.

Frota-Pessoa (2008) admite que "estudando também as relações entre a comunidade e o ambiente físico, estaremos tratando do ecossistema como um todo" (p.68). A estrutura fechada aparece nitidamente o que permite classificá-la tradicional. Em seguida afirma que "o aspecto de um ecossistema depende das características de solo e clima cada local e das espécies que nele se instalaram" (p.68). Aqui, percebe-se, mais uma vez, estrutura fechada, pois considera-se apenas o solo e o clima do local, bem como a influência das espécies que ali vivem, enquadrando-a na concepção tradicional.

No livro de Paulino (2008) há a seguinte definição de ecossistema: "Conjunto formado pela comunidade e pelo meio ambiente. O ecossistema - considerado a unidade ecológica básica compreende o conjunto das interações dos seres vivos de uma comunidade entre si e com os diversos fatores físico-químicos do meio ambiente, como temperatura e água" (p. 217). Desta maneira, o autor concebe o ecossistema como unidade isolada e fechada, caracterizando-a como tradicional. 
Os contrastes derivados da análise estão no quadro 3 a seguir. Nota-se que, exceto um livro, os demais apresentam a concepção tradicional de ecossistema. No entanto, em três deles foi também encontrada a visão contemporânea.

Quadro 3. Resultado da análise da concepção de ecossistema nos livros didáticos de biologia

\begin{tabular}{|c|c|c|}
\hline Obra analisada & Concepção tradicional & Concepção contemporânea \\
\hline Adolfo, Crozeta e Lago (2005) & $\mathrm{X}$ & \\
\hline Amabis e Martho (2009) & $\mathrm{X}$ & $\mathrm{X}$ \\
\hline César e Sézar (2005) & $\mathrm{X}$ & \\
\hline Favaretto e Mercadante (2005) & $\mathrm{X}$ & $\mathrm{X}$ \\
\hline Frota-Pessoa (2008) & $\mathrm{X}$ & \\
\hline Laurence (2005) & $\mathrm{X}$ & $\mathrm{X}$ \\
\hline Linhares e Gewandsjander (2008) & $\mathrm{X}$ & \\
\hline Lopes e Mendonça (2006) & $\mathrm{X}$ & \\
\hline Paulino (2008) & & \\
\hline
\end{tabular}

Deste modo, a resposta à questão - "como o livro didático caracteriza os fenômenos do mundo, em seu nível mais básico?" é a de que há predomínio da concepção tradicional de ecossistema em livros didáticos de biologia do ensino médio. Conseqüentemente, o conceito de ecossistema em tais livros indica o compromisso dos autores com a visão de mundo sustentada por uma metafísica de substância. Todavia, esta concepção metafísica não é a mais apropriada para a ecologia, embora o seja para outras disciplinas, tais como a bioquímica.

\section{Considerações finais}

Procuramos esclarecer sobre os fundamentos metafísicos da biologia propagados pelo livro didático de biologia, recorrendo ao conceito ecossistema. Não foi nossa intenção a de avaliar as concepções metafísicas mais adequadas à biologia e nem a de avaliar os livros didáticos analisados. Portanto, nossos resultados não implicam em juízos de valor.

A estratégia de análise que empregamos é promissora quanto ao objetivo de desvelar visões de mundo propagadas por livros didáticos. No entanto, muito ainda há para se fazer quanto à análise de livros didáticos e seus compromissos filosóficos. Mais ainda, devemos 
questionar até que ponto as visões de mundo, propagadas por meio das escolas e dos livros didáticos, estão em consonância com as visões de mundo da biologia científica contemporânea.

Além de ser uma área promissora para pesquisas em ensino de biologia, também pode colaborar na construção de estratégias alternativas de ensino e configurações curriculares. Isto porque conhecer as visões de mundo propagadas pela biologia científica e da biologia escolar pode facilitar entendimento de conceitos da Biologia contemporânea.

\section{Referências}

Adolfo, A.; Crozeta, M. e Lago, S. Biologia. São Paulo: IBEP. 2005.

Amabis, J. M. e Martho, G. R. Biologia das Populações. São Paulo: Moderna. 2009.

Bardin, L. Análise de conteúdo. Lisboa: Edições 70. 2000.

Clements, F. E. Plant Succession: An Analysis of the Development of Vegetation. Washington: Carnegie Institution of Washington. 1916.

Dewey J. Science as subject-matter and as method. Science 31:121-127. Reproduzido em Science \& Education 1995 : 4(4):391-398. 1910.

Dewitt, R. Wolrdview. Malden: Wiley-Blackwell. 2010.

Emmeche, C. e El-hani, C. N. Definindo Vida. In: El-Hani, C. N. e Videira, A. A. P. (Orgs.). O que é vida? Para Entender a Biologia do Século XXI. Rio de Janeiro: Relume Dumará.pp. 31-56. 2000.

Favaretto, J. A. e Mercadante, C. Biologia. São Paulo: Moderna. 2005.

Ferré, F.. Being and value. Toward a constructive postmodern metaphysics. Alabany: State University of New York Press. 1996.

Frota-Pessoa, O. Biologia 2. São Paulo: Editora Scipione. 2008.

Hovardas, T. e Korfiatis, K. Towards a critical re-appraisal of ecology education: scheduling na educational interviention to revisit the 'balance of nature' metaphor. Science \& Education. DOI 10.1007/s11191-010-9325-0. 2010.

Hustwit, J. R. Process Philosophy. Internet Encyclopedia of Philosophy. Disponível em http://www.iep.utm.edu/processp/ (Acesso em 29/12/2010). 2007.

Kawasaki, C. S. e El-hani, C. Uma análise das definições de vida encontradas em livros didáticos de biologia do Ensino Médio. Coletânea do VIII Encontro Perspectivas do Ensino de Biologia. São Paulo: USP. CD-ROM. 2002.

Ladyman, J. Understanding philosophy of science. London: Routledge, 2002.

Laurence, J. 2005. Biologia. São Paulo: Nova Geração. 2005.

R. B. E. C. T., vol 4, núm 2, mai./ago. $2011 \quad$ ISSN - 1982-873X 
Lear, J. Aristotle: the desire to understand. Cambridge: Cambridge University Press. 1995.

Linhares, S. e Gewandsznajder, F. Biologia Hoje. São Paulo: Ática. 2008.

Lopes, S. e Mendonça, V. L. Bio - volume 3. São Paulo: Saraiva. 2006.

Lowe, E. J. Metaphysics as the Science of Essence. Disponível em

http://ontology.buffalo.edu/06/Lowe/Lowe.pdf. 2006.

MatthewS, M. R. Teaching the philosophical and worldview components of science. Science \&

Education. DOI 10.1007/s11191-007-9132-4. 2009.

O'neill, R. V. Is it time to bury the ecosystem concept? (With full military honors, of course!).

Ecology, 82 (12): 3275-3284, 2001.

Paulino, W. R. Biologia 3. São Paulo: Ática. 2008.

Peacock, K. A. Ecosysten. In: Sahotra, S. and Plutynski, A. A Companion to the Philosophy of Biology, pp. 351-367. Oxford: Wiley-Blackwell, 2011.

Peirce, C. S. The architecture of theories. In: Browning, D. e Myers, W. T. Philosophers of process. Pp. 4-14. New York: Fordham University Press. 1998 [1935].

Reale, G. História da filosofia antiga. (Cinco volumes). São Paulo: Loyola. 1994 .

Reiners, W. A. e Lockwood, J. A. Philosophical Foundations for the Practices of Ecology.

Cambridge: Cambridge University Press. 2009.

Rescher, N. Process metaphysics. Albany: State University of New York Press. 1996.

Rescher, N. Process philosophy. Pittsburgh: University of Pittsburgh Press. 2000.

Rescher, N. Process philosophy. Stanford Encyclopedia of Philosophy. Disponível em:

http://plato.stanford.edu/entries/process-philosophy/. (Acesso: 03/07/09). 2008.

Ross, D. Aristóteles. Lisboa: Dom Quixote. 1997.

Silva, C. J. e Sasson, S. Biologia 3. São Paulo: Saraiva. 2005.

Tansley, A. G. The use and abuse of vegetational terms and concepts. Ecology 16 (3): 284-307, 1935.

Tseitlin, M. and Galili, I. Science teaching: what does it mean? Science \& Education, 15 (5), 393417, 2006.

Ulanowicz, R. E. A third window. Natural life beyond Newton and Darwin. West Conshohocken: Templeton Foundation Press. 2009.

Whitehead, A. N. Process and reality. New York: Macmillan. 1978 [1929]. 
Francisco Ângelo Coutinho. Universidade Federal de Minas Gerais Faculdade de Educação.

Departamento de Métodos e Técnicas de Ensino. Doutor em Educação pela Universidade Federal de Minas Gerais. fac01@terra.com.br

Rogério Parentoni Martins. Universidade Federal do Ceará (UFC). Centro de Ciências

Departamento de Biologia. Doutorado em Ecologia pela Universidade Estadual de Campinas.

wasp@icb.ufmg.br

Raquel Reis Winter. Acadêmica do Curso de Ciências Biológicas, Instituto de Ciências Biológicas Universidade Federal de Minas Gerais.quelwinter@yahoo.com.br

Fernanda de Jesus Costa. Fundação Helena Antipoff. Professora da Fundação Helena Antipoff. Mestrado em Ensino de Ciências e Matemática pela Pontifícia Universidade Católica de Minas Gerais.fernandinhajc@yahoo.com.br 